\title{
Criteria for the definition and classification of complex post-incision hernias
}

\author{
Criterii de definire şi clasificare a herniilor postincizionale complexe
}

\section{Roxana-Florina Ristea ${ }^{1}$, Nicoleta-Aurelia Sanda ${ }^{2}$, Daniel Ion ${ }^{1,3}$, Radu Şerban Palade ${ }^{3}$}

1Secţia de Chirurgie Generală III, Spitalul Universitar de Urgenţă, Bucureşti

${ }^{2}$ Secţia de Chirurgie Generală II, Spitalul Universitar de Urgenţă, Bucureşti

3UMF „Carol Davila“, Bucureşti

\begin{abstract}
Recurrence after postinicizsional hernia surgery is an unsolved problem so far. In literature the hernia rec-curence varies between $1 \%$ and $50 \%$, influenced by the postoperative follow-up period. The purpose of this paper is to describe the term „complex postincisional hernia“. It becomes necessary to clarify the term and make a classification in order to be able to apply a surgical treatment adapted to the patient's plurifactorial pathology and to allow comparison of the results between the different surgical methods. This paper is a review of the literature on this subject, obtained through the use of EPOS, NCBI, PubMed, MedLine, Embase and other international databases.
\end{abstract}

Keywords: postincisional complex hernia, herniar reccurence, classification

\section{REZUMAT}

Recidiva după chirurgia herniilor postincizionale este o problemă nerezolvată până în momentul de faţă. Datele din literatura de specialitate privind recidivele variază între $1 \%$ şi $50 \%$, fiind influenţate de perioada de urmărire postoperatorie. Scopul lucrării de faţă este precizarea termenului de „hernie postincizională comple-xă“. Devine necesară clarificarea termenului şi efectuarea unei clasificări pentru a putea aplica un tratament chirurgical adaptat patologiei plurifactoriale a pacientului şi a permite compararea rezultatelor între diferitele metode terapeutice chirurgicale utilizate.

Lucrarea de faţă este un review al literaturii de specialitate pe această temă, obţinut prin folosirea EPOS, NCBI, PubMed, MedLine, Embase şi a altor baze de date internaţionale.

Cuvinte cheie: hernie postincizională complexă, recidivă, clasificare

\section{INTRODUCERE}

Herniile postincizionale reprezintă cea mai frecventă ,complicaţie tardivă““ a laparotomiilor. Acestea apar cel mai frecvent în primii cinci ani (1) după intervenţia iniţială, iar dezvoltarea lor este corelată cu multipli factori de risc.

\section{Factori de risc pentru apariția herniilor postincizionale (2-6)}

1. Factorii de risc ce ţin de pacient:

a) Factori de risc majori: BPOC, obezitate, diabet zaharat, malnutriţia protein-calorică, hipoalbuminemia, icterul, radiotera- pia, chimioterapia, anticoagulantele orale, fumatul.

b) Factori de risc minori: sexul masculin, ventilaţia mecanică postoperatorie, insuficienţa renală, bolile de ţesut conjunctiv, neoplazia, transfuziile de sânge, anemia.

2. Factorii de risc ce implică plaga operatorie: perturbări ale metabolismului colagenului, procent scăzut de colagen tip III/tip I, expresie crescută a MMP-2 activă, închiderea peritoneului, laparotomia mediană, infecţia de plagă.

3. Factorii de risc legaţi de închiderea laparotomiei: raportul dintre firul de sutură şi lungimea plăgii $<4 / 1$, închiderea cu paşi mici, 
tensiune crescută la nivelul peretelui abdominal, relaparotomie la mai puţin de o lună de zile, mai mult de două laparotomii/an.

4. Factorii ce ţin de modul de prezentare al bolnavului: urgenţă, sângerare, traumatism, sepsis abdominal.

5. Factorii relaţionaţi cu stresul postoperator sau stresul mecanic: tuse, distensie abdominală, efort fizic intens, efort de defecaţie, vomă.

6. Factorii de risc corelaţi cu laparoscopia: diametrul trocarelor $>10 \mathrm{~mm}$, inserţii multiple, durată crescută a intervenţiei, cantităţi mari de fluide restante în cavitatea peritoneală, evacuarea inadecvată a pneumoperitoneului, perete abdominal nerelaxat la finalul intervenţiei, presiune abdominală crescută la finalul intervenţiei.

7. Alţi factori de risc: complicaţii postoperatorii, profilaxia antibiotică, chirurgul, extensia follow-up-ului, utilizarea electrocauterului.

Cei mai importanţi factori de risc implicaţi în dezvoltarea herniilor postinicizionale sunt reprezentaţi de obezitate, vindecarea defectuoasă a plăgii de laparotomie, malnutriţia şi fumatul $(5,6)$. Având în vedere faptul că patogeneza bolii este una plurifactorială, trebuie menţionat că ischemia tisulară locală este un factor extrem de important. Există, de asemenea, cauze mai puţin frecvente, cum ar fi imunosupresia, bolile de metabolism ale colagenului şi bolile de ţesut conjunctiv de tipul anevrismelor de aortă abominală, sindromul Ehlers-Danlos $(7,8)$. Un factor de risc extrem de important este chiar chirurgul, prin tehnica folosită la închiderea laparotomiei. Orice patologie ce conduce la creşterea frecventă sau persistentă a presiunii intraabdominale contribuie la dezvoltarea herniilor postincizionale.

Herniile postincizionale apar de obicei în primii 3-5 ani de la intervenţia chirurgicală iniţială, astfel: aproximativ 50\% în primii doi ani şi până la $74 \%$ în primii 3 ani (9-11).

În Germania, aproximativ 50.000 de pacienţi cu hernii incizionale sunt supuşi unei intervenţii chirurgicale corectoare anual, în SUA, numărul acestora este de aproximativ 350.000/an (12,13). Având în vedere numărul mare de intervenţii corectoare realizate, impactul economic generat este imens. În SUA, costurile intervenţiilor au fost calculate la 3,2 miliarde de dolari/an $(12,13)$.

Recidiva după chirurgia herniilor postincizionale este o problemă nerezolvată până în momentul de faţă. Datele din literatura de specialitate privind recidivele variază între $1 \%$ şi 50\%, fiind influenţate de perioada de urmărire postoperatorie $(4,14)$. Soluţionarea recidivelor prin sutură se pare că oferă rezultate de două ori mai slabe decât repararea prin protezare, deşi chiar şi în condiţiile folosirii meşelor, recidivele rămân frecvente, atingând valori uneori mai mari de $20 \%$ (14).

Lipsa consensului în definirea termenului de hernie postincizională complexă îngreunează elaborareaa unor protocoale terapeutice standardizate, identificarea pacienţilor ce necesită îngrijire specializată şi obţinerea de rezultate comparabile între diversele procedee de tratament chirurgical.

Scopul lucrării de faţă este precizarea a termenului de ,hernie postincizională complexă“". Devine necesară clarificarea termenului şi efectuarea unei clasificări pentru a putea aplica un tratament chirurgical adaptat patologiei plurifactoriale a pacientului şi a permite compararea rezultatelor între diferitele metode terapeutice chirurgicale utilizate.

\section{MATERIAL ŞI METODE}

Lucrarea de faţă este un review al literaturii de specialitate pe această temă, obţinut prin folosirea EPOS, NCBI, PubMed, MedLine, Embase și a altor baze de date internaţionale.

Am studiat în mod particular lucrări publicate în perioada 1998-2018, atât articole originale, cât şi sinteze din literatura de specialitate.

\section{REZULTATE}

Deşi termenul de hernie postincizională complexă este din ce în ce mai des folosit, până în momentul de faţă nu există o definiţie general valabilă a acestei entităţi. Herniile postincizionale complexe sunt caracterizate în mod particular de existenţa unor anumiţi factori de risc general, de particularităţi anatomice şi/sau a corelării cu procesul infecţios. În mod obişnuit, se decelează concomitent mai mulţi factori de risc. Frecvent, herniile postincizionale sunt hernii recidivate, la pacienţi cu istoric de evoluţie complicată postoperatorie. De asemenea, tratamentul în sine al acestei patologii prezintă riscul apariţiei complicaţiilor, în mod frecvent fiind întâlnită o vindecare postoperatorie defectuoasă a plăgii sau recidivă (15).

Tratamentul herniilor postincizionale complexe reprezintă un exemplu etalon al unui abord chirurgical adaptat. Herniile complexe reprezintă o provocare chirurgicală, tratamentul lor necesitând întregul spectru de tehnici şi echipamente de care dispune operatorul (inclusiv colaborarea interdisciplinară cu chirurgii plasticieni). În funcţie de di- 
mensiuni, cura chirurgicală variază de la sutura simplă cu aproximarea marginilor defectului aponevrotic (pentru defectele mai mici de $3 \mathrm{~cm}$ ) (16), la reconstrucţii majore ale peretelui abdominal ce implică realizarea de lambouri musculare şi folosirea unor proteze de mari dimensiuni. Aceste deziderate pot fi obţinute atât prin abord deschis, cât şi pe cale laparoscopică.

În urma sistematizării datelor din literatura de specialitate, am precizat şi elaborat o serie de sisteme de clasificare a herniilor postincizionale întâlnite.

\section{Sistemele de clasificare a herniilor postincizionale în literatură}

În 1998, Sharma et al. (17) au realizat o clasificare anatomică a defectelor peretelui abdominal bazată pe localizarea herniei şi au configurat o „hartă“ a potenţialelor regiuni ,donatoare“ de lambouri musculare pentru închiderea fiecărei zone în parte.

Linia orizontală trecută prin ombilic împarte peretele abdominal într-o regiune supra şi una subombilicală, iar două linii verticale trecute medioclavicular împart fiecare regiune într-o zonă centrală şi două zone laterale, rezultând în total şase regiuni. De asemenea, autorii clasifică defectele şi după dimensiune: $<100 \mathrm{~cm}^{2}, 100-200 \mathrm{~cm}^{2},>200 \mathrm{~cm}^{2}$.

În anul 2000, Chevrel şi Rath (18) raportează un sistem de clasificare cu valoare predictivă bazânduse pe analiza statistică a unui studiu retrospectiv pe 435 de pacienţi. Această clasificare şi-a propus să identifice criterii de recomandare pentru reconstrucţia peretelui abdominal în manieră autologă sau nonautologă. După analiza corespunzătoare a datelor, au creat o clasificare ce include localizarea herniei postincizionale (medial sau lateral), dimensiunea măsurată prin lăţimea defectului $(<5 \mathrm{~cm}$, $5-10 \mathrm{~cm}, 10-15 \mathrm{~cm}$ şi $>15 \mathrm{~cm})$ şi dacă hernia este sau nu recidivată. Iniţial, au realizat o împărţire a herniilor mediale în supra, juxta şi infraombilicale şi hernii postincizionale xifo-pubiene. Herniile postincizionale laterale au fost împărţite în subcostale, transversale, iliace şi lombare. S-a concluzionat că nu există corelaţie între localizare şi recidivă, luând în considerare şi faptul că în unele localizări există un grad mai mare de utilizare a protezării. De asemenea, autorii susţin că numărul recidivelor nu este important în ceea ce priveşte rezultatul. Considerând că lăţimea herniei este un parametru mai important decât lungimea, în vederea alegerii tehnicii şi a rezultatului procedeului corector, au susţinut faptul că un calcul al suprafeței defectului herniar utilizând ca parametri lungimea şi lăţimea nu ar trebui folosit, deoarece acest calcul ar putea genera o încadrare în acceaşi categorie a unor hernii cu o suprafață identică, dar al căror rezultat în cazul aplicării aceleiaşi tehnici chirurgicale va fi diferit, deci a căror abordare ar trebui să fie distinctă. Acest grup de lucru a luat în considerare şi importanţa unor alte variabile implicate în rezultatul final al abordării unei hernii postincizionale: vârsta, anemia, malnutriţia, patologia sistemică, tratamentul steroidian, radioterapia, tehnica de închidere anterioară a laparotomiei şi complicaţiile, în principal sepsisul şi infecţiile de plagă.

Tot în 2000, Rohrich şi colaboratorii (19) au realizat o clasificare a defectelor peretelui abdominal, menită să permită chirurgului plastician să dezvolte un algoritm de abordare în vederea intervenţiei corectoare. Clasificarea implică folosirea termenului de profunzime a defectului parietal: parţial (tegumentar sau musculo-fascial) sau complet (defect ce implică toată grosimea peretelui, inclusiv tegumentul). După localizare, defectul a fost divizat în lateral sau medial, iar mai apoi ca aparţinând treimii superioare, mijlocii sau inferioare a peretelui abdominal, rezultând astfel 6 regiuni distincte (sau 9, dacă se contorizează separat dreapta şi stânga). În cele din urmă, mărimea defectului a fost clasificată în funcţie de lăţime, pentru diversele locaţii, ca fiind $<5 \mathrm{~cm}, 5-15 \mathrm{~cm},>15 \mathrm{~cm}$. Au fost luate în considerare şi contaminarea sau infecţia plăgii. De asemenea, autorii au luat în discuţie importanţa factorilor de risc, incluzând funcţia pulmonară, în relaţie strânsă cu pierderea dreptului la domiciliu, factorii ce influenţează vindecarea plăgii, cum ar fi imunosupresia, dependenţa de medicaţia steroidiană, statusul nutriţional, fumatul şi consumul de alcool.

În 2001, Korenkov şi colegii săi (20) au raportat rezultatele discuţiilor întâlnirii unei comisii de experţi, sub auspiciile Societăţii Europene de Herniologie din 1998, cu scopul de a încerca să răspundă la întrebările curente legate de herniile postincizionale. În ceea ce priveşte clasificarea, următoarele variabile au fost folosite drept criterii: localizarea, dimensiunea, recurenţa, reductibilitatea şi simptomatologia. Localizarea (modificată după clasificarea iniţială a lui Chevrel şi Rath) (18) împarte herniile postincizionale în verticale (de linie mediană, supra şi subombilicale, de linie mediană, incluzând regiunea ombilicală dreaptă sau stângă, paramediane drepte sau stângi), transversale (supra sau subombilicale drepte sau stângi, care depăşesc linia mediană sau nu), oblice (supra sau subombilicale, drepte sau stângi) şi combinări ale categoriilor de mai sus. Dimensiunea a fost împărţită în trei ca- 
tegorii: mici, medii şi mari $(<5 \mathrm{~cm}, 5-10 \mathrm{~cm},>10$ $\mathrm{cm}$, în lungime sau lăţime). În afara numărului de recidive, se mai contorizează modalitatea de reparare anterioară. În ceea ce priveşte situaţia locală la nivelul defectului herniar, se notează dacă hernia este reductibilă sau ireductibilă şi dacă este sau nu ocluzivă. În cele din urmă, se notează prezenţa sau nu a simptomatologiei. Autorii iau în discuţie faptul că o abordare chirurgicală reparatorie individualizată este de o importanţă crucială şi va fi necesar să se ia în discuţie o pleiadă de factori locali şi generali, pentru a genera cea mai bună soluţie a cazului.

În 2005, Ammaturo şi Bassi sugerează un nou parametru de clasificare, pornind de la dimensiunile herniei (21). Raportul dintre suprafaţa peretelui abdominal (surface of the abdominal wall - SAW) şi suprafaţa defectului parietal (wall defect surface - WDS) a fost adăugată clasificării lui Chevrel şi Rath. Un raport scăzut SAW/WDS a fost asociat în mod semnificativ cu o presiune intraabdominală crescută, conducând la tensiune crescută la nivelul peretelui abdominal, factor sugerat ca un surogat important în predicţia apariţiei recidivei herniare. Montarea intraperitoneală prin abord deschis a unei meșe, fără desfiinţarea defectului, a dus la o scădere importantă a presiunii intraabdominale, comparativ cu montarea retromusculară a protezei, în manieră Rives-Stoppa.

În 2006, Chowbey et al. (22) au propus o clasificare a herniilor ventrale bazată pe gradul de dificultate intraoperatorie preconizat, în eventualitatea unei intervenţii laparoscopice. Autorii au elaborat un sistem de clasificare cu şapte grade (1-7) bazat pe: hernia este primară, incizională sau recidivată, conţinutul sacului herniar şi reductibilitatea acestuia, gradul de obstrucţie (subacută), incizii anterioare multiple, abdomen cicatricial, dimensiune şi localizare. Autorii nu au adus explicaţii suplimentare în ceea ce priveşte modul de construcţie al sistemului de clasificare sau al alegerii variabilelor.

În 2006, Dietz şi colaboratorii au dezvoltat un sistem de clasificare în scopul de a permite evaluarea comparativă a rezultatelor pe termen lung şi în scopul de a emite indicaţii şi a evidenţia limitări ale diverselor tehnici de abord chirurgical (3). Sistemul de clasificare include patru parametri: recurenţa, localizarea, mărimea (lăţime şi lungime) şi factorii de risc pentru recidivă. Factorii de risc includ obezitatea, sexul masculin, fumatul, contaminarea plăgii, vârsta, complicaţiile postoperatorii. Morfologia ia în discuţie localizarea herniei - după criteriile impuse de Chevrel şi Rath (18) - şi diferite tipuri constituţionale bazate pe unghiul subcostal, tonusul muscular şi volumul abdomenului. Ţinând cont de tipul constituţional, diverse tehnici chirurgicale devin mai mult sau mai puţin adecvate. De exemplu, mobilizarea laterală a fost considerată ca imposibil de realizat în cazul pacienţilor astenici sau la cei cu un unghi sternocostal îngust. Atrofia musculară întâlnită la vârstnici este considerată factor de risc. Bazându-se pe date de literatură, autorii au emis indicaţii în ceea ce priveşte modalitatea uzuală de corectare a herniilor incizionale, evidenţiind, de asemenea, factorii ce le limitează aplicabilitatea.

În 2006, Conze şi grupul său de lucru (23) au emis un sistem de clasificare, bazat pe prognostic, pentru herniile postincizionale. Acest sistem împarte herniile în trei grupuri terapeutice, bazându-se pe dimensiune, localizare, hernie primară sau recidivată (tipurile I-III).

- Tipul I: hernie primară sau postincizională necomplicată, cu un defect parietal $<3 \mathrm{~cm}$, ce poate fi tratată convenţional prin sutură cu material neresorbabil.

- Tipul II: hernie postincizională cu defect < $10 \mathrm{~cm}$ sau cu defecte multiple şi hernie postincizională recidivată după reparare anterioară prin sutură, hernii la care se stabileşte indicaţia de reparare prin protezare retromusculară.

- Tipul III: hernie postincizională complexă cu defect aponevrotic $>10 \mathrm{~cm}$ şi distanţa faţă de planul osos $<3 \mathrm{~cm}$, la care se indică folosirea unui procedeu combinat de separare a componentelor şi proteză montată retromuscular.

În 2009, Muysoms şi colaboratorii (24) au prezentat clasificarea herniilor primare şi incizionale elaborată de Societatea Europeană de Herniologie. A fost creat un grup de consens şi, în urma întâlnirii şi discuţiilor, a fost elaborată o grilă de clasificare. În clasificarea herniilor primare este inclusă localizarea (epigastrică, ombilicală, spigeliană, lombară) şi dimensiunea $(<2 \mathrm{~cm}, 2-4 \mathrm{~cm},>4 \mathrm{~cm})$. Această clasificare va rămâne în afara discuţiilor ulterioare. $\mathrm{Nu}$ s-a obţinut un consens în ceea ce priveşte clasificarea herniilor postincizionale, dar s-a încercat obţinerea unei scale de clasificare, bazată pe localizare, dimensiune, recidivă. Herniile mediale au fost împarţite în cinci zone: subxifoidiene, epigastrice, ombilicale, subombilicale şi suprapubiene. Regiunile laterale, de ambele părţi, au fost definite ca: subcostale, flancuri (transversale în clasificarea lui Chevrel şi Rath (18)), iliace şi lombare. Nu a fost obţinut consensul în ceea ce priveşte dimensiunea. Lăţimea a fost împărţită în următoarele grupe: $<4$ $\mathrm{cm}, 4-10 \mathrm{~cm},>10 \mathrm{~cm}$, dar măsurătorile exacte ale lăţimii şi lungimii au rămas un subiect deschis discuţiei. În cazul prezenţei unor defecte multiple, s-a 
propus folosirea dimensiunilor unei linii orizontale şi a uneia verticale între cele mai îndepărtate margini ale defectului. Numărul recidivei nu a fost considerat suficient de important pentru a fi inclus în criteriile de definire, fiind înregistrat $\mathrm{cu}$ „Da“ sau "Nu“.

În 2010, Breuing şi colegii săi au creat Sistemul de clasificare al grupului de lucru asupra herniilor ventrale (Ventral Hernia Working Group - VHWG), ce constă în patru grade (1-4) şi are la bază factorii de risc, statusul privind contaminarea şi infecţia. Ţelul acestui grup a fost să identifice pacienţii cu risc crescut de a dezvolta o hernie postincizională, bazându-se pe caracteristicile bolnavului şi ale herniei (25). Ipoteza luată în discuţie a fost: complicaţiile postoperatorii, în special cele infecţioase, cresc riscul de apariţie a recidivei herniilor postincizionale. Definiţia pe grade a categoriilor incluse în clasificare este următoarea:

- gradul I - risc scăzut (risc mic de complicaţii, fără istoric de infecţie de plagă);

- gradul II - comorbidităţi (fumat, obezitate, diabet, BPOC, imunosupresie);

- gradul III - potenţial contaminată (infecţie de plagă anterioară, prezenţa unei stome, deschiderea tractului gastrointestinal);

- gradul IV - infectată (proteză infectată, dehiscenţă de plagă în context septic).

Autorii recunosc ca există şi alţi factori care pot influenţa riscul de complicaţii şi recidivă, dar concluzionează ca nu există suficiente date în literatură care să permită cuantificarea riscului de recurenţă herniară corelat cu aceşti factori. De asemenea, formulează recomandări în ceea ce priveşte tehnica terapeutică optimă şi alegerea materialului protetic în funcţie de clasificarea generată şi îşi susţin algoritmul pe baza datelor obţinute din literatura de specialitate. De curând, grupul Rosen a încercat să valideze sistemul de clasificare VHWG determinând riscul real al complicaţiilor de plagă (SSO), aplicând criteriile stabilite anterior unui grup de 299 de pacienţi ce au fost supuşi intervenţiilor chirurgicale curative. Rezultatele obţinute au evidenţiat faptul că, deşi clasificarea VHWG s-a dovedit eficientă în stratificarea pacienţilor în grupuri cu risc independent de a dezvolta o complicaţie de plagă, compararea grupurilor în contiguitate ( $\operatorname{grad} 2$ vs. grad 3 şi grad 3 vs. grad 4) nu a relevat diferenţe statistice semnificative în ceea ce priveşte apariţia acestora. Autorii au sugerat diverse modificări pentru a creşte puterea de predicţie a algoritmului creat. Istoricul de imunosupresie ( $\operatorname{grad} 2)$ nu a relevat importanţă statistică în predicţia complicaţiilor de plagă şi a fost îndepărtat din criterii. În plus, prin modifi- carea încadrării ,istoricului de infecţie de plagă““ în gradul 2 şi ,,prezenţa unei stome“ şi ,nerespectarea integrităţii tractului intestinal “ în gradul 4, au fost obţinute diferenţe semnificative la compararea gradului 2 cu gradul 4. Practic, aceste modificări transformă sistemul de clasificare cu patru grade întrunul cu trei grade:

- gradul 1 - ,risc scăzut““ (risc scăzut de complicaţii, fără istoric de infecţii de plagă);

- gradul 2 - „,comorbidităţi““ (fumat, obezitate, diabet, cu istoric de infecţii de plagă)

- gradul 3-A-curat - contaminat, B - contaminat, $\mathrm{C}$ - murdar. Recidivele (surgical site occurrence) au apărut în $14 \%, 27 \%$, respectiv $46 \%$ dintre cazuri la pacienţii încadraţi în aceste categorii (25).

În 2011, Hadeed a realizat o clasificare bazată pe un sistem cu 5 grade, asemănător celui realizat de Breuing et al. (12), bazat pe variabilele: factori de risc, contaminare, infecţie şi pierderea dreptului la domiciliu. Gradele 1 şi 2 sunt aceleaşi folosite în clasificarea Breuing, în timp ce gradul 3 include într-o singură grupă gradele 3 şi 4 din clasificarea Breuing (contaminare şi infecţie). În plus, adaugă două noi grupe :

- gradul 4 - pentru pacienţii cu scăderi ponderale majore;

- gradul 5 - pacienţii cu hernii postincizionale cu pierderea dreptului la domiciliu cu sau fără comorbidităţi.

Autorii susţin că pacienţii cu scăderi ponderale marcate au un risc crescut de vindecare defectuoasă a plăgii operatorii, incluzând riscul asociat unei eventuale dermolipectomii concomitente.

În 2013, Slater et al. organizează o echipă de lucru, ce cuprinde chirurgi experimentaţi în patologia peretelui abdominal, în încercarea de a stabili un sistem de clasificare şi a identifica variabilele ce interferă cu alegerea tratamentului şi prognosticul pacientului (15). Stadializarea a fost făcută având drept criterii de includere în categoria herniilor postincizionale complexe patru categorii de factori:

- dimensiuni şi localizare;

- contaminare/ condiţia ţesuturilor moi;

- istoricul pacientului/factori de risc;

- tabloul clinic.

În încercarea de a genera indicaţii legate de atitudinea perioperatorie, riscul de complicaţii postoperatorii şi costurile generate de tratamentul unui astfel de bolnav, aceste variabile au fost stratificate în trei clase de severitate:

- minor

- moderat

- major 
TABELUL 1. Criterii de definire a herniilor postincizionale complexe (15)

\begin{tabular}{|c|c|}
\hline 1. Dimensiuni şi localizare & $\begin{array}{l}\text { Lățime > } 10 \mathrm{~cm} \\
\text { Localizare parastomală, lombară, laterală, subcostală } \\
\text { Pierderea dreptului la domiciliu }>20 \%\end{array}$ \\
\hline $\begin{array}{l}\text { 2. Contaminare şi condiția } \\
\text { țesuturilor moi }\end{array}$ & $\begin{array}{l}\text { Plagă chirurgicală contaminată (clasa III) sau infectată (clasa IV) } \\
\text { Defecte parietale ce implică întreaga grosime a peretelui } \\
\text { Pierderile de substanță (după rezecție tumorală, traumatisme, infecții) } \\
\text { Anatomie distorsionată (multiple intervenții în antecedente) } \\
\text { Denervare musculară } \\
\text { Grefe de piele } \\
\text { Ulcere cutanate / plăgi trenante } \\
\text { Abdomen deschis } \\
\text { Afecțiuni asociate (omfalocel, fasceită necrotizantă) } \\
\text { Prezența fistulelor entero-cutanate }\end{array}$ \\
\hline $\begin{array}{l}\text { 3. Istoricul pacientului şi } \\
\text { factori de risc }\end{array}$ & $\begin{array}{l}\text { Recidiva herniară după intervenția corectoare aloplastică sau separarea componentelor } \\
\text { Comorbidități / factori de risc ce afectează vindecarea plăgii: obezitate, diabet, vârsta înaintată, utilizarea de } \\
\text { steroizi, status nutrițional deficitar (albumina }<30 \mathrm{~g} / \mathrm{dl} \text { ) } \\
\text { Presiune intraabdominală crescută: obezitate, BPOC } \\
\text { Istoric de dehiscență a plăgii } \\
\text { Istoric de infecție a meşei }\end{array}$ \\
\hline 4. Tablou clinic & $\begin{array}{l}\text { Intervenție de urgență ce asociază rezecție intestinală } \\
\text { Suprimarea unei proteze intraperitoneale } \\
\text { Defecte herniare multiple ("battle-scared abdomen”) } \\
\text { Imposibilitatea închiderii primare a plăgii operatorii în absența separației componentelor }\end{array}$ \\
\hline
\end{tabular}

În 2016, Petro şi Novitsky propun un sistem de clasificare simplificat, similar sistemului TNM utilizat în stadializarea patologiei neoplazice (26), ce utilizează trei variabile - hernia, pacientul şi plaga. În generarea acestui sistem a fost folosită tomografia computerizată ca instrument de evaluare preoperatorie a pacientului.

Sistemul caracterizează elementele ce ţin de hernie $(\mathrm{H})$ utilizând ca unic parametru lăţimea $(\mathrm{H} 1$ $<10 \mathrm{~cm}, \mathrm{H} 2=10-20 \mathrm{~cm}, \mathrm{H} 3>=20 \mathrm{~cm}$ ), comorbidităţile pacientului - P (P0 = fără comorbidităţi; P1 = prezenţa a cel puţin una din următoarele: obezitate morbidă, diabet, fumat şi/sau imunosupresie) şi factori legaţi de plaga operatorie (W - wound; W0 = curată; $\mathrm{W} 1$ = contaminată). Este astfel posibilă generarea unui tabel multidimensional plecând de la aceste trei variabile, rezultatul fiind un sistem de stadializare cu patru clase în funcţie de riscul de dezvoltare a infecţiilor de plagă (SSI) şi a recurenţei herniare.

TABEL 2. Clasificarea HPW ( Hernie-Pacient-Plagă) (26)

\begin{tabular}{|l|l|l|l|l|}
\hline & Hernie & Pacient & Plagă (W) & Stadializare HPW \\
\hline Stadiu I & 1 & 0 & 0 & H1, P0, W0 \\
\hline Stadiu II & 1 sau 2 & Oricare & 0 & $\begin{array}{l}\text { H1, P1, W0 } \\
\text { H2, orice P, W0 }\end{array}$ \\
\hline Stadiu III & Oricare & Oricare & 0 sau 1 & $\begin{array}{l}\text { H1, orice P, W1 } \\
\text { H2, orice P, W1 } \\
\text { H3, P0, W0 }\end{array}$ \\
\hline Stadiu IV & 3 & Oricare & 0 sau 1 & $\begin{array}{l}\text { H3, P1, W0 } \\
\text { H3, orice P, W1 }\end{array}$ \\
\hline
\end{tabular}

Sistemul rezultat este uşor de amintit, vast, bazat pe dovezi şi oferă informaţii atât pe termen scurt, legate de complicaţiile de plagă, cât şi informaţii legate de eficienţa pe termen lung - recidiva.

Această clasificare încearcă să includă principalele variabile implicate în evaluarea preoperatorie - hernia, pacientul şi plaga, excluzând elementele descoperite intraoperator.

\section{CONCLUZII}

În concluzie, multiplele sisteme şi scale de clasificare trasate până în prezent concură la crearea unui sistem uniform de clasificare, ce permite includerea sau excluderea diverselor criterii în evaluarea şi optimizarea perioperatorie a tehnicii chirurgicale reparatorii şi a alegerii protezei.

Următorul pas în tratamentul herniilor postincizionale complexe va fi legat de crearea şi validarea unor algoritmi de tratament, care să includă indicaţii privind tehnica şi tipul de proteză adaptate cazului. 


\section{BIBLIOGRAFIE}

1. Bernard C, Polliand C, Mutelica L, Champault G. Repair of giant incisional abdominal wall hernias using open intraperitoneal mesh. Hernia, 2007 Aug;11(4):315-20.

2. Yahchouchy-Chouillard E, Aura T, Picone O, Etienne JC, Fingerhut A. Incisional hernias: I. Related risk factors. Digestive Surgery 2003;20(1):3-9.

3. Dietz UA, Hamelmann W, Winkler MS, Debus ES, Malafaia O, Czeczko NG et al. An alternative classification of incisional hernias enlisting morphology, body type and risk factors in the assessment of prognosis and tailoring of surgical technique. J Plast Reconstr Aesthet Surg. 2007;60(4):383-8.

4. Dietz UA, Winkler MS, Härtel RW, Fleischhacker A, Wiegering A, Isbert $C$ et al. Importance of recurrence rating, morphology, hernial gap size, and risk factors in ventral and incisional hernia classification. Hernia. 2014 Feb;18(1):19-30.

5. Isik A, Peker K, Gursul C, Sayar I, Firat D, Yilmaz I et al. The effect of ozone and naringin on intestinal ischemia/reperfusion injury in an experimental model. Int J Surg. 2015 Sep;21:38-44.

6. Isik A, Peker K, Soyturk M, Firat D, Yoruker U, Yilmaz I. Diagnostic Evaluation and Treatment of Patients With Rectus Abdominis Hematoma. Cirugía Española (English Ed. 2015, Nov;93(9):580-8.

7. Van 'T Riet M, De Vos Van Steenwijk PJ, Bonjer HJ, Steyerberg EW, Jeekel J. Incisional hernia after repair of wound dehiscence: Incidence and risk factors. Am Surg. 2004 Apr;70(4):281-6.

8. Girotto JA, Malaisrie SC, Bulkely G, Manson PN. Recurrent ventral herniation in Ehlers-Danlos syndrome. Plast Reconstr Surg. 2000 Dec;106(7):1520-6.

9. Lamont PM, Ellis $\mathrm{H}$. Incisional hernia in reopened abdominal incisions: An overlooked risk factor. Br J Surg. 1988 Apr;75(4):374-6.

10. Bucknall TE, Cox PJ, Ellis $H$. Burst abdomen and incisional hernia: $A$ prospective study of 1129 major laparotomies. Br Med J (Clin Res Ed). 1982 Mar 27;284(6320):931-3.

11. Anthony T, Bergen PC, Kim LT, Henderson M, Fahey T, Rege RV et al. Factors affecting recurrence following incisional herniorrhaphy. World J Surg. 2000 Jan;24(1):95-101.

12. Hadeed JG, Walsh MD, Pappas TN, Pestana IA, Tyler DS, Levinson H et al. Complex abdominal wall hernias: A new classification system and approach to management based on review of 133 consecutive patients. Ann Plast Surg. 2011 May;66(5):497-503.

13. Bower $C$, Roth JS. Economics of abdominal wall reconstruction. Surg Clin North Am. 2013 Oct;93(5):1241-53.
14. Luijendijk RW, Hop WCJ, van den Tol MP, de Lange DCD, Braaksma MMJ, IJzermans JNM, et al. A Comparison of Suture Repair with Mesh Repair for Incisional Hernia. New England Journal of Medicine, $2000343(6), 392-398$.

15. Slater NJ, Montgomery A, Berrevoet F, Carbonell AM, Chang A, Franklin $\mathrm{M}$ et al. Criteria for definition of a complex abdominal wall hernia. Hernia, 2014 Feb;18(1):7-17.

16. Kingsnorth A, LeBlanc K. Hernias: Inguinal and incisional. Lancet, 2003 Nov 8;362(9395):1561-71.

17. Sharma RK, Singh G, Naidu PM. Abdominal wall defects: Anatomic classification and a scheme for management. Ann Plast Surg. 1998 Aug;41(2):180-4.

18. Chevrel JP, Rath AM. Classification of incisional hernias of the abdominal wall. Hernia, March 2000, Volume 4, Issue 1, pp 7-11.

19. Rohrich RJ, Ha RY, Kenkel JM, Adams WP. Classification and management of gynecomastia: Defining the role of ultrasound-assisted liposuction. Plast Reconstr Surg. 2003 Feb;111(2):909-23; discussion 924-5.

20. Korenkov M, Neugebauer E. Classification and surgical treatment of incisional hernia: Results of an experts' meeting. Langenbecks Arch Surg. $2001 \mathrm{Feb} ; 386(1): 65-73$.

21. Ammaturo $C$, Bassi $G$. The ratio between anterior abdominal wall surface/wall defect surface: A new parameter to classify abdominal incisional hernias. Hernia, 2005 Dec;9(4):316-21.

22. Chowbey PK, Khullar R, Mehrotra M, Sharma A, Soni V, Baijal M. Sir Ganga Ram Hospital classification of groin and ventral abdominal wall hernias. J Minim Access Surg. 2006 Sep;2(3):106-9.

23. Conze J, Junge K, Klinge U, Schumpelick V. Evidenzbasierte laparoskopische chirurgie - Narbenhernie. Viszeralchirurgie, 2006, 41(4):246-252.

24. Muysoms FE, Miserez M, Berrevoet F, Campanelli G, Champault GG, Chelala $E$ et al. Classification of primary and incisional abdominal wall hernias. Hernia, 2009 Aug; 13(4): 407-414.

25. Breuing K, Butler CE, Ferzoco S, Franz M, Hultman CS, Kilbridge JF et al. Incisional ventral hernias: Review of the literature and recommendations regarding the grading and technique of repair. Surgery, 2010, Sep;148(3):544-58.

26. Petro CC, Novitsky YW. Classification of Hernias. In: Hernia Surgery: Current Principles. Springer International Publishing, 2016. 